\title{
THE EFFECT OF THE SPECIMEN-PLATEN INTERFACE ON INTERNAL CRACKING AND BRITTLE FRACTURE OF ICE UNDER COMPRESSION: HIGH-SPEED PHOTOGRAPHY
}

\author{
By E.M. Schulson, M.C. Gies, G.J. LAsonde, and W.A. Nixon*
}

(Thayer School of Engineering, Dartmouth College, Hanover, New Hampshire 03755, U.S.A.)

ABSTRACT. Uniaxial compression experiments at $-10^{\circ} \mathrm{C}$ at $10^{-3} \mathrm{~s}^{-1}$ on fresh-water, granular ice have established through the use of high-speed photography that internal cracks nucleate preferentially away from the ice/platen $(i / p)$ interface under conditions of $\mathrm{i} / \mathrm{p}$ contraint, but near the interface under conditions of $i / p$ expansion. Under conditions of little $\mathrm{i} / \mathrm{p}$ interaction, cracks nucleate more or less randomly throughout the specimen. Correspondingly, the brittle-fracture strength decreases as the $\mathrm{i} / \mathrm{p}$ interaction changes from compressive to tensile. These effects are explained in terms of the spatial variation of the maximum shear stress and the crack density.

\section{INTRODUCTION}

The purpose of this paper is to show through the use of high-speed photography that both the distribution of internal cracks and the macroscopic fracture mode of ice rapidly strained under uniaxial compression are affected by the stress state at the ice/platen $(i / p)$ interface. The work is part of a larger study on the effects of stress state on the fracture of ice, and serves as the basis for developing non-interactive loading platens. Also, it helps to relate the behavior of ice to that of other materials.

\section{EXPERIMENTAL PROCEDURE}

Cylindrical specimens (101.6 $\mathrm{mm}$ diameter by $\sim 250 \mathrm{~mm}$ ) of equiaxial and randomly oriented aggregates of freshwater ice were prepared from pre-sieved seeds and from distilled, de-ionized and degassed water, as described elsewhere (Lee and Schulson, 1988). They were characterized by a density of $916 \pm 1 \mathrm{~kg} / \mathrm{m}^{3}$ at $-10 \mathrm{C}$ and by a grainsize of $d=4.5 \pm 0.6 \mathrm{~mm}$ (as determined using the method of linear intercepts).

Three different $i / p$ stress states were investigated. Radial confinement was effected by bonding discs of stainless steel $(101.6 \mathrm{~mm}$ diameter by $31 \mathrm{~mm})$ to the specimens, the ends of which had been made parallel by milling to within $0.025-0.040 \mathrm{~mm}$. Radial expansion was effected by inserting a thin $(0.2 \mathrm{~mm})$ sheet of latex rubber between the milled ends of the ice and brass plates $(9 \mathrm{~mm}$ by $138 \mathrm{~mm}$ by $138 \mathrm{~mm}$ ). The faces of the plates had been milled parallel to within $0.025 \mathrm{~mm}$ and then polished to the level of 600 grit using metallurgical polishing papers. A near-zero interaction was effected by compressing specimens between a pair of brass brushes. The ends of the specimens had been milled parallel. The brushes have been described elsewhere (Gies, unpublished). They were modeled after the ones described by Häusler (1982) and comprised 784 bristles (each $4.8 \mathrm{~mm}$ by $4.8 \mathrm{~mm}$ by $178 \mathrm{~mm}$ ) arranged in a square, grid-like array (Fig. 3g).

* Present address: Iowa Institute of Hydraulic Research, University of Iowa, Iowa City, Iowa, U.S.A.
The specimens were compressed at $-10^{\circ} \mathrm{C}$ at a constant strain-rate of $10^{-3} \mathrm{~s}^{-1}$ using a servohydraulic loading system (MTS model 810.14) housed within a cold room. The temperature was controlled to better than $\pm 0.2^{\circ} \mathrm{C}$. The strain-rate was maintained by averaging the output from two displacement gages and by using the average to control the velocity of the actuator.

Representative specimens were filmed at a speed of $1000 \mathrm{frames} / \mathrm{s}$ under frontal lighting of $2400 \mathrm{~W}$. No filters were used.

\section{RESULTS}

Figures 1, 2, and 3 show the sequence of crack development, the macroscopic fracture modes, and the respective stress-strain curves. The cracks are the bright spots in the images and not the glare or long, bright, vertical lines which result from reflections from the curved surface of the specimens. The photographs are "spotty". The images, nevertheless, reveal the following features:

(i) Under radial confinement (Fig. 1), cracks about equal in size to the grain-size develop initially at random sites within the central section. The first ones appear at an axial stress of approximately $2-3 \mathrm{MPa}$ and additional ones continue to nucleate as the stress rises. All are stable. Eventually, macroscopic fracture/failure occurs through the development of a shear fault (Fig. 1e) which passes through the more heavily damaged, central section of the specimen. The broken pieces are milky in appearance, owing to the high number density of the internal cracks, and usually contain axial cracks that stopped within the end zones. Clear conical regions of base slightly smaller than the diameter of the specimen and about $2-3 \mathrm{~cm}$ deep are evident within both end zones, showing that the induced radial stress suppresses crack nucleation and implying that the confinement of the ends approaches "full confinement". The macroscopic fracture surfaces are granular in character, of a scale similar to the grain-size, and are covered by a layer of very finely granulated ice or "ice powder" which probably develops as one surface slides over the other.

(ii) Under radial expansion (Fig. 2), cracks develop initially within the end zones, i.e. where radial stresses are induced of a sense opposite to those induced under confinement. Again, the first cracks form at an axial stress of approximately $2-3 \mathrm{MPa}$ and additional, stable ones nucleate as the stress rises. The influence of the stress state within the ends of the specimen, as in the above case, is exerted throughout the entire loading history, as evident from the hour-glass shape of the crack pattern (Fig. 2b-d). The gradation in opacity between the ends and the center of the specimen is lower than it is for the case of confinement, implying that the magnitudes of the induced radial stresses are lower in this case. Eventually, failure occurs through axial splitting or cleavage (Fig. $2 \mathrm{~g}$ ) along a plane which passes within the central volume of the specimen. The split develops via the rapid growth of a 


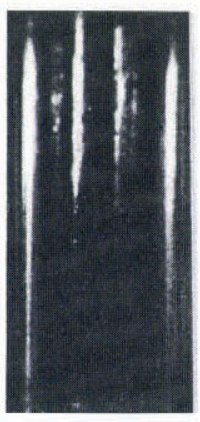

a

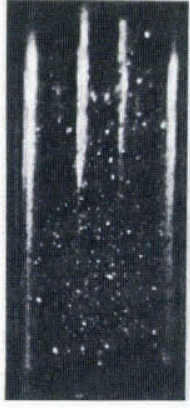

b

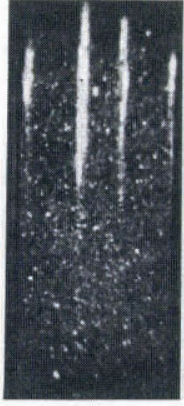

C

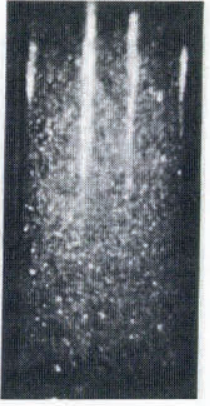

d

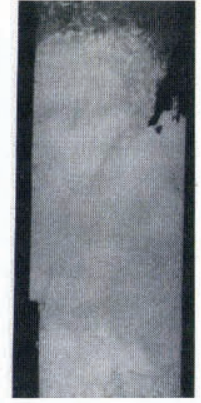

e

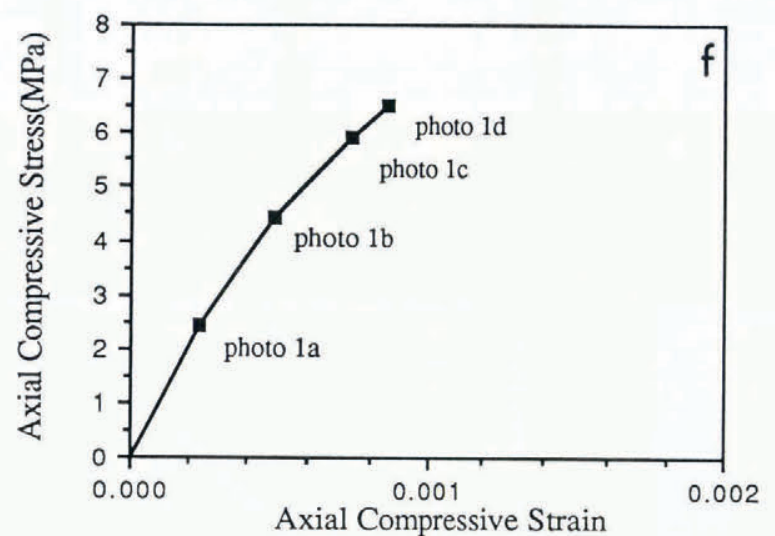

Fig. 1. a-d. Photographs of fresh-water granular ice compressed at $-10^{\circ} \mathrm{C}$ at $10^{-3} \mathrm{~s}^{-1}$ between bonded stainless steel caps (not shown), taken from a high-speed film (1000 frames $/ \mathrm{s})$. Note the higher concentration of cracks within the central part of the specimen. e. Photograph showing a macroscopic shear fault. f. The stress-strain curve for the specimen shown in $(a-e)$.

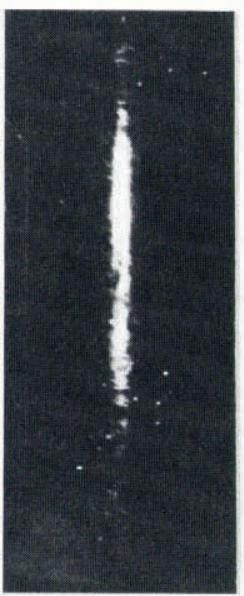

a

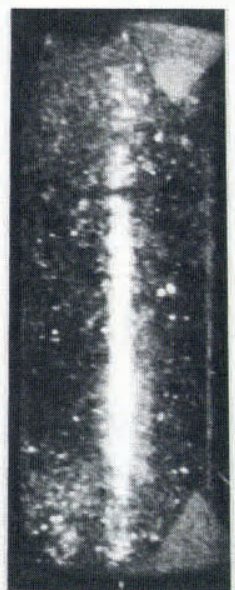

b

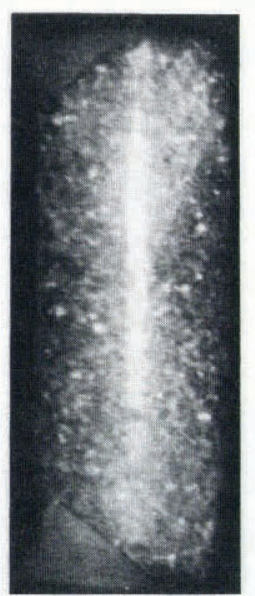

c

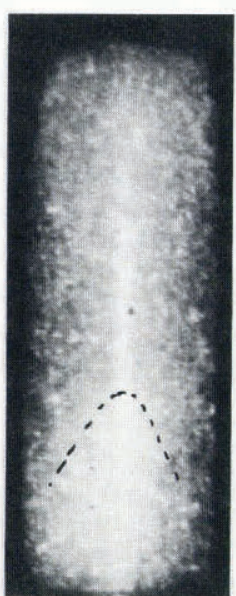

$d$

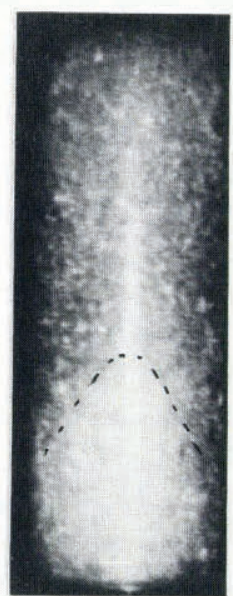

e

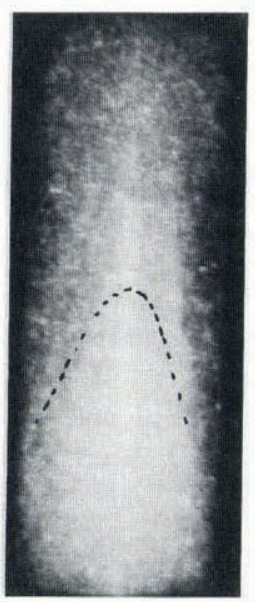

f

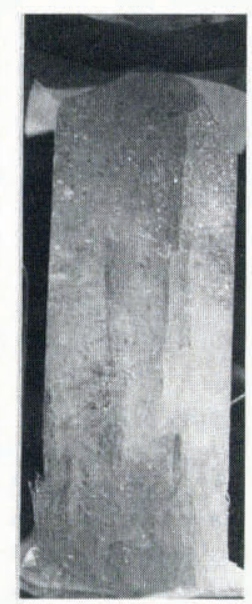

g

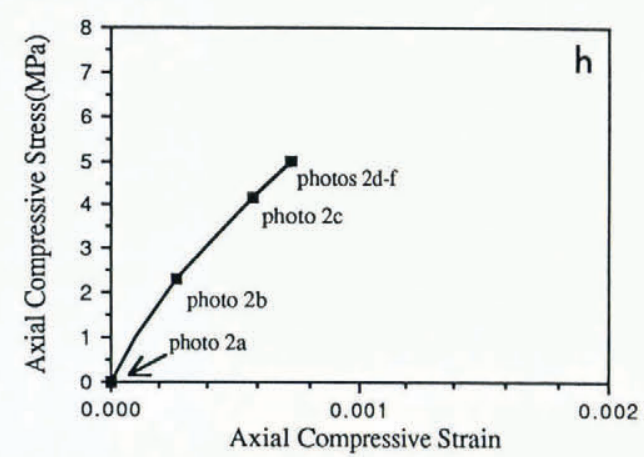

Fig. 2. a-f. As Figure 1, for a specimen compressed between polished brass platens separated by latex inserts (shown in $(\mathrm{g})$ ). Note the higher concentration of cracks near the ends of the specimen. g. Photograph showing macroscopic axial splitting or cleavage. $h$. The stress-strain curve for the specimen shown in $(a-g)$. 


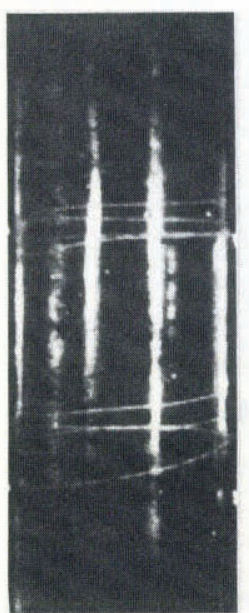

a

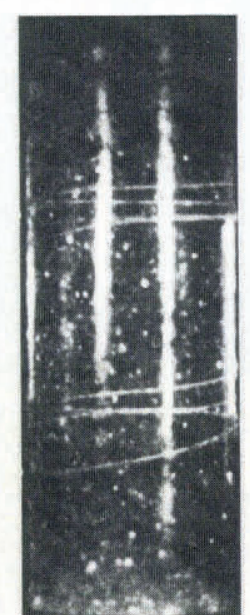

b

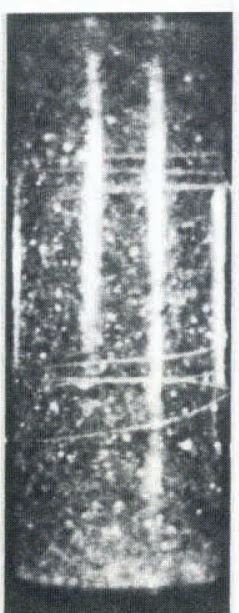

c

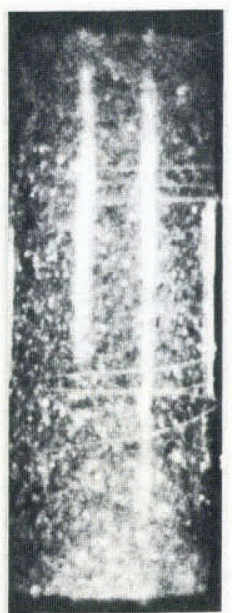

d

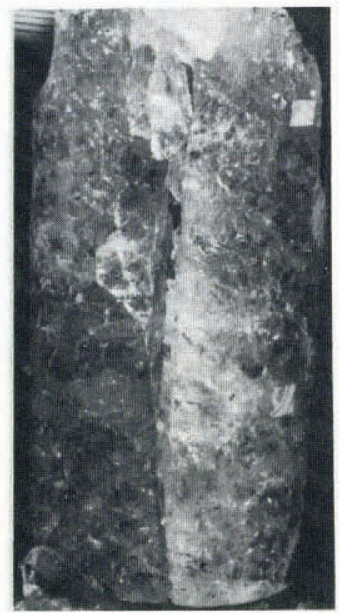

e
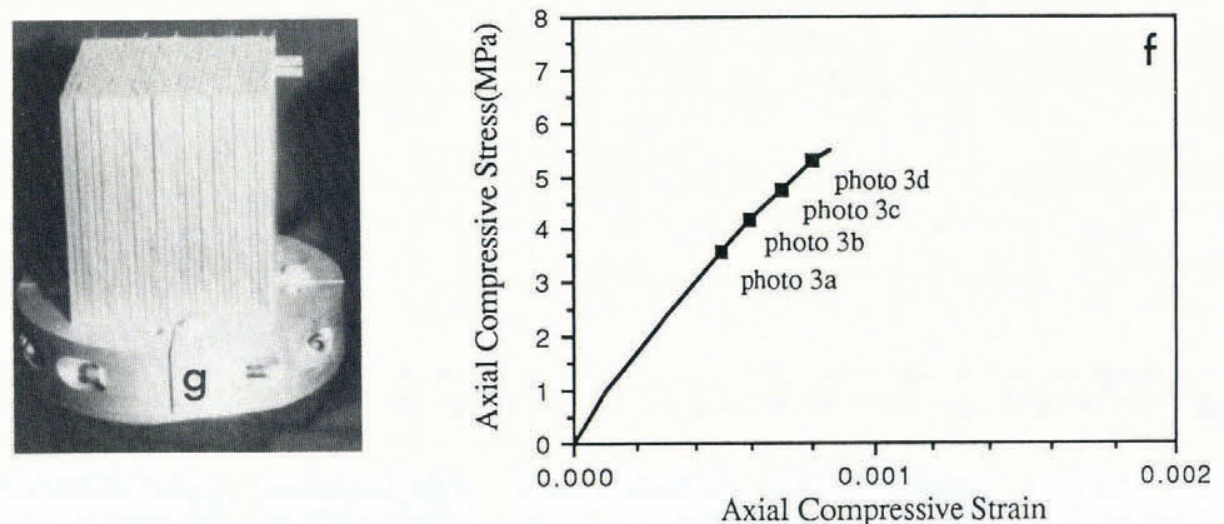

Fig. 3. $a-d$. As Figure 1, for a specimen compressed between brush-type brass platens. Note the rather uniform concentration of cracks throughout the specimen. e. Photograph showing axial splitting. $f$. The stress-strain curve of the specimen shown in $(a-e)$. g. Photograph of a brush-type platen.

macroscopic crack out of one of the heavily damaged end zones, as evident from the appearance on the three frames (Fig. $2 \mathrm{~d}-\mathrm{f}$ ) prior to collapse of an advancing curved interface which separates milky from very milky ice. The approximate position of the interface is shown by the broken lines on Figure $2 \mathrm{~d}-\mathrm{f}$, and appears to advance at the rate of about $30 \mathrm{~m} / \mathrm{s}$. The location and the shape of the interface presumably mirror the variation of the stress-intensity factor for crack opening (i.e. mode-I loading). The opacity or milkiness of specimens which fracture under radial expansion is less than it is for specimens which fracture under radial confinement (Fig. $2 \mathrm{~g}$ vs le), implying that fewer cracks nucleate before failure occurs. Also, the fracture surfaces, although still granular, are essentially free from "ice powder".

(iii) Under conditions of near-zero $\mathrm{i} / \mathrm{p}$ constraint (Fig. 3), cracks develop more or less randomly throughout the entire volume of the specimen. Again, the first cracks appear at an axial stress of approximately 2-3 MPa and macroscopic failure occurs through axial splitting (Fig. 3e) along a plane or planes which pass through the central region of the specimen. The end faces of the specimens reveal no grid-like pattern of cracking (Fig. 4), suggesting that the bristles do not significantly enhance crack nucleation. Again, the fractured specimens are less milky than those fractured under radial constraint, and the fracture surfaces are essentially free from powder.

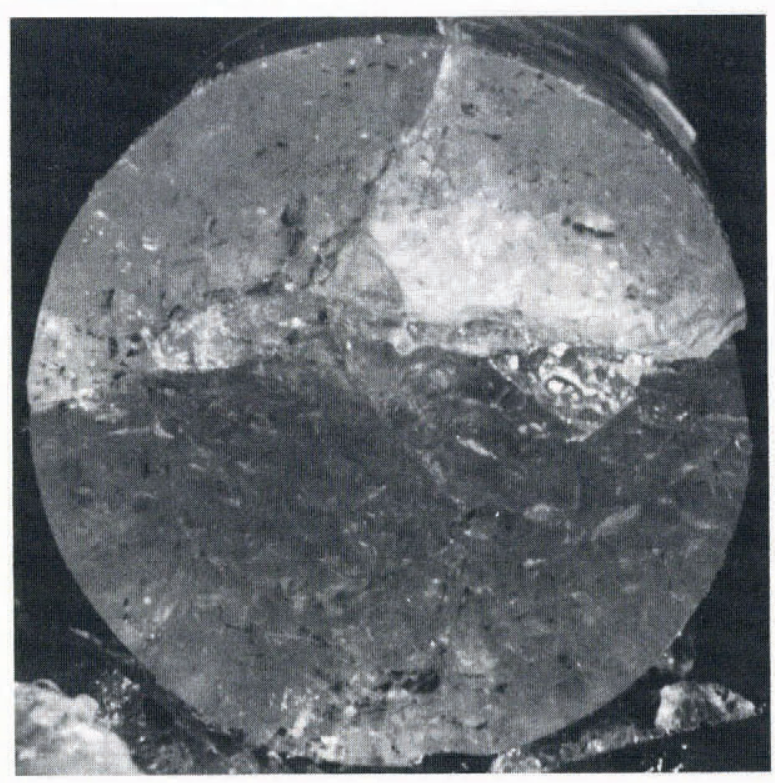

Fig. 4. Photograph of one end of a test specimen fractured between the brush-type platens. Note the absence of a grid-like pattern of cracks. 
Multiple tests of the above conditions revealed that the brittle-fracture strength is affected by the ice/platen interaction. Under radial confinement the strength is the highest, and under radial expansion the lowest (Table I). The variation about the value obtained using the relatively non-interacting brush platens is around $10-15 \%$. This trend reflects the variation in opacity noted above.

TABLE I. BRITTLE COMPRESSIVE STRENGTH AT $-10^{\circ} \mathrm{C}$ AT $10^{-3} \mathrm{~s}^{-1}$ OF EQUIAXED, FRESH-WATER POLYCRYSTALLINE ICE Ih OF $4.5 \pm 0.6 \mathrm{~mm}$ GRAINSIZE VERSUS ICE/PLATEN INTERFACE

\begin{abstract}
Ice-platen interface
\end{abstract}
Number
of tests

Fracture

strength

Standard

$\mathrm{MPa}$

$\mathrm{MPa}$

Bonded stainless steel

6.36

(radial confinement)

Brush platens

4

5.54

0.34

Rubber insert

7

4.98

(radial expansion)

\section{DISCUSSION}

When viewed within the context of the compressive fracture of brittle materials, the results are not surprising. Chelmsford granite (Peng and Johnson, 1972) and Tennessee marble (Wawersik, unpublished), for instance, exhibit similar variations with end conditions in the pattern of internal cracking, in the macroscopic failure mode and in the fracture strength. Ice may be typical of brittle solids and, thus, may provide insight into the fracture of different kinds of materials.

Concerning failure modes, questions arise about axial splitting. Is it a true failure mode? Or is it caused by stress concentrations at the $\mathrm{i} / \mathrm{p}$ interface? The present observations show that splitting occurs when the internal damage is more or less uniform (i.e. when the specimens are compressed between the brush platens) and that this mode operates in the absence of preferential end-face cracking beneath the bristles. The view is taken, therefore, that axial splitting is a true failure mode. This is not to say, however, that whenever axial splitting occurs there is no $\mathrm{i} / \mathrm{p}$ interaction, for as is apparent from the present work and from the earlier work on rocks (Peng and Johnson, 1972; Wawersik, unpublished), splitting can be induced when outward radial stresses are developed within the ends of the specimen. This mechanism occurs at a crack density lower than that at which shear faulting occurs, accounting for the attendant lower strength.

Another issue concerns the measure taken of the compressive strength under a uniaxial state of stress. Many measurements have been made under uniaxial loading, either by bonding to end caps of one material or another or by creating dumb-bell-shaped specimens. Under conditions where the behavior is ductile and where the length-to-diameter ratio is sufficiently great, the end effects are insignificant (Lasonde and others, 1988). In such cases, one $i / p$ system is probably as good as another. On the other hand, under conditions where the behavior is brittle, as in the present case, bonding to end caps or reducing the cross-section leads to inward radial stresses, which lead to over-measures of the unconfined brittle compressive strength, even in specimens for which the length-todiameter ratio is as large as 2.5. Thus, for accurate measurements under conditions which lead to brittle behavior, it is perhaps better to use radially compliant platens, such as the brush platens used here.

It could be argued that in cases where bonded end caps are made from a material having a ratio of Young's modulus $(E)$ to Poisson's ratio $(v)$ similar to that for the test specimen and where the caps are thick and of the same diameter as the specimen, the radial stresses are negligible. Certainly, they will be smaller than for the case of "full confinement". However, the stresses will only be truly negligible in the elastic region. When cracks form, the aggregate becomes more compliant, $E / v$ begins to decrease, and radial stresses develop. For instance, the phenolic based material "Synthane" has an $E / v$ ratio of $18-27 \mathrm{GPa}$, compared ot $26 \mathrm{GPa}$ for ice and $670 \mathrm{GPa}$ for stainless steel. Yet, when "Synthane" is used for end caps on ice, a pattern of internal cracking develops which is very similar to that observed for the steel platens. Subsequently, macroscopic fracture occurs through shear faulting at an axial stress $(5.62 \pm 0.73 \mathrm{MPa})$ which lies between the fracture stresses measured using the bonded steel and the brush platens (Lasonde, unpublished).

Not addressed so far is the question of the length to diameter ratio, $L / D$. This point was considered elsewhere (Lasonde and others, 1988). Cylindrical specimens (101.6 mm diameter) of fresh-water, columnar ice (of random orientation of the $c$-axes normal to the columns) were compressed along the columns at $-10^{\circ} \mathrm{C}$ at $10^{-3} \mathrm{~s}^{-1}$ (i.e. in the brittle regime). $L / D$ was varied from 2.5 to 1.25 . When the ice was bonded to "Synthane", the strengths of the long and the short specimens, respectively, were $12.7 \pm 2.5$ and $13.8 \pm 2.0 \mathrm{MPa}$. When the ice was compressed between the brush platens, the strengths of the long and the short specimens were $10.6 \pm 1.0$ and $11.3 \pm 1.9 \mathrm{MPa}$, respectively. These strengths are higher than those for the granular ice, reflecting the anisotropic character of the columnar ice. Also, they again reflect the influence of end confinement. However, they suggest that within the scatter in the data the $L / D$ ratios examined here have little or no effect on compressive strength measured using either bonded "Synthane" or brush platens.

As noted above, the pattern of internal cracking reflects the presence (or absence) of induced radial stresses. In more fundamental terms, the pattern probably reflects the spatial variation of the maximum shear stress. Supporting this view is the conical shape of the crack-free end zones within the specimens bonded to the stainless steel, and the hour-glass shape of the heavily cracked zones within the specimens separated from the platens by the latex inserts. In both cases, the equilibrium equations show that the maximum shear stress is given approximately as one-half the difference in principal stresses, $\frac{1}{2}\left(\sigma_{r}-\sigma_{a}\right)$, where $\sigma_{r}$ is the radial normal stress and $\sigma_{\mathrm{a}}$ is the axial normal stress $\left(\sigma_{\mathrm{a}}<0\right) ; \quad \sigma_{\mathrm{r}}=0$ at the surface of the specimen and approaches zero across the mid-section. In the first case, $\sigma_{\mathrm{r}}<0$ near the ends, and so the maximum shear stress within regions bounded by the surface of a cone and based at the ends of the specimen does not reach the value necessary for crack nucleation before the more central part becomes sufficiently damaged to trigger shear faulting. In this case, judging from the clarity of the conical shaped end zones, the induced stresses are relatively large. In the second case, $\sigma_{\mathrm{r}}>0$, and so the shear stress necessary for crack nucleation is reached within conical shaped end zones before being reached within the central section. The magnitude of the induced stress in this case is smaller, judging from the rather small difference in the opacity of the specimen between.its ends and mid-section.

The mechanism(s) of crack nucleation, the subsequent growth and interaction of such cracks, and the detailed processes of shear faulting and axial splitting are beyond the scope of the present discussion. Suffice it to say that preliminary considerations (Schulson, 1987) suggest that the processes are probably not unique to ice.

\section{CONCLUSION}

Compression experiments aided by high-speed photography have shown that platens which constrain the ends of test specimens lead to internal cracking away from the end zones and eventually to brittle compressive failure through shear faulting. Platens which expand the ends, on the other hand, lead to preferential cracking near the ends and to failure through axial splitting at a lower applied stress. Platens which have little interaction with the ice lead to a uniform distribution of cracking and to axial splitting at an intermediate applied stress. These effects can be understood in terms of the nucleation of cracks, the spatial variation of the maximum shear stress, and the crack density. 


\section{ACKNOWLEDGEMENTS}

The authors wish to acknowledge G.A. Kuehn for experimental assistance and $\mathrm{F}$. Willett for discussions.

This study was supported by the U.S. Office of Naval Research. The experiments were performed in Dartmouth's Ice Research Laboratory, which is operated with additional support from the U.S. Army Research Office, United States Coast Guard, Minerals Management Service, Amoco Production Company, Conoco Inc., Exxon Production Research Company, Mobil Research and Development Corporation, Shell Development Company, and Unocal Corporation.

\section{REFERENCES}

Gies, M.C. Unpublished. The development of brush-type platens for loading ice specimens in compression. (M.E. thesis, Dartmouth College. Thayer School of Engineering, 1988.)

Häusler, F.U. 1982. Multiaxial compressive strength tests on saline ice with brush-type loading platens. In IAHR. International Symposium on Ice, Québec 1981. Proceedings.
Vol. 2. Québec, Université Laval, 526-539.

Lasonde, G.J. Unpublished. The effects of end constraint on the strength and fracture mode of polycrystalline ice in compression. (M.E. thesis, Dartmouth College. Thayer School of Engineering, 1988.)

Lasonde, G.J., M.C. Gies, and E.M. Schulson. 1988. The effects of end conditions on the strength and fracture of ice under compression. In Saeki, H. and K.-i. Hirayama, eds. Proceedings, the 9th International Symposium on Ice, 23-27 August 1988, Sapporo, Japan. Vol. 1. Delft, International Association for Hydraulic Research. Committee on Ice Problems, 99-108.

Lee, R.W. and E.M. Schulson. 1988. The strength and ductility of ice under tension. J. Offshore Mech. Arct. Eng., 110, 187-191.

Peng, S.D. and A.M. Johnson. 1972. Crack growth and faulting in cylindrical specimens of Chelmsford granite. Int. J. Rock Mech. Min. Sci., 9, 37-86.

Schulson, E.M. 1987. The fracture of ice Ih. J. Phys. (Paris), 48, Colloq. C1, 207-220. (Supplément au 3.)

Wawersik, W.R. Unpublished. Detailed analyses of rock failure in laboratory compression specimens. (Ph.D. thesis, University of Minnesota, 1968.) 